\title{
THE USE EFFECTIVENESS OF THE COPPER T-200 IN MATLAB, BANGLADESH
}

\author{
U. ROB ${ }^{a}$, J.F. PHILLIPS ${ }^{b}$, J. CHAKRABORTY ${ }^{c}$ and M.A. KOENIG ${ }^{b, c}$ \\ ${ }^{a}$ Department of Population Planning and International Health University of Michigan, Ann Arbor (USA), bPopulation Council \\ Associate, Bangkok (Thailand) and 'International Center For Diarrhoeal Disease Research (Bangladesh).
}

(Received June 12th, 1986)

(Accepted October 17th, 1986)

\begin{abstract}
Using a unique record keeping system, the use effectiveness of the Copper T-200 is examined in rural Bangladesh. In Matlab the Copper T-200 is a highly effective contraceptive modality. The adopters are typically low to medium parity women under 30 years of age. The most important cause of termination among women in the study was voluntary removal of the device. The complaint most often reported was bleeding followed by pain and weakness. The Matlab experience suggests that sustained motivation and regular resupply are the two key components of this highly successful family planning program.
\end{abstract}

Keywords: Copper T-200; Continuation; Termination; Expulsion; Pregnancy; Removal; Side-effect.

\section{Introduction}

The Copper T-200 is an intrauterine contraceptive device made of polythelene, shaped like the letter $\mathrm{T}$ with a $200 \mathrm{~mm}$ copper wire wound around the vertical stem. The device owes its origin to studies carried out in the late 1960s, which demonstrated both the advantage of the $T$ configuration as well as the antifertility effect of copper. Tatum first hypothesized that the $T$ shape would be retained in the uterus without altering the shape of the endometrium. Clinical trials of the
Tatum $T$ showed that it was associated with significantly less pain and bleeding than the popular Lippes Loop D and with markedly reduced expulsion rates. Failure rates however, were unacceptably high with this method, and it becomes apparent that to be effective the $T$ would have to carry an antifertility agent [11].

In 1969, Zipper et al. reported that copper and zinc placed in the uterus of rabbits inhibited pregnancy [14]. This finding led to a series of animal studies on the effect of metal upon fertility, which demonstrated that copper had a greater anti-fertility effect than other metals. When further laboratory research demonstrated the safety of coppcr, a series of clinical studies were carried out to determine the effectiveness of the Copper $T$ and the optimal amount of copper to use in the device [15]. These early clinical studies suggested that the Copper $\mathrm{T}$ was more effective than the Lippes Loop; pregnancy, expulsion and removal rates were significantly lower among Copper $\mathrm{T}$ users than among users of the Lippes Loop D [4,12]. These encouraging findings from the early clinical studies prompted a series of international studies to determine the effectiveness of the Copper $T$ in a variety of settings. In this paper, findings from one such recent study in rural Bangladesh are presented.

The only known previous study of the Copper $T$ in Bangladesh was a comparison of the Copper T-220C and the Lippes Loop, based on data from about 300 acceptors of 
each device [3]. This study was conducted in a population of women attending a family planning clinic in urban Bangladesh and indicated that the Copper $\mathrm{T}$ had higher continuation rates than the Lippes Loop among women accepting IUDs immediately after menstrual regulation (MR) and approximately the same continuation rates as the Lippes Loop among women who were not post-MR acceptors. Both pregnancy and expulsion rates were lower for the Copper $T$ group than for the loop users. Removal rates were similar for both devices with the exception of removal for heavy bleeding, which was higher for the Copper $T$ group (although not statistically significant). The authors hypothesized that this might be due to the large amount of copper in the $220 \mathrm{C}$, and perhaps could be avoided by using a $\mathrm{T}$ with less copper. Evidence from this urban study suggests that the Copper $T$ might be a suitable one-time method for use in Bangladesh. The current study, carried out in Metlab, represents an assessment of the efficacy of the Copper $\mathrm{T}$ in a rural setting.

\section{Materials and Methods}

The International Centre for Diarrhoeal Disease Research, Bangladesh (ICDDR,B) has been conducting community-based family planning programs since 1975 . Work was initially confined to the distribution of oral pills and condoms in Matlab, an approach which was found to have only limited efficacy [6]. To overcome the deficiencies of the contraceptive distribution program, the field structure and program activities were modified in October 1977 to provide a full range of contraceptive methods to women at their doorstep [1]. After a brief period of experimentation with the Lippes Loop, this device was abandoned in favor of the Copper $\mathrm{T}$, which has continued as the IUD of choice to the present day. The current Matlab service program encompasses 70 villages with a population of 90000 ; in addition to a central clinic, there are four subcentre clinics in
Matlab, each serving a population of slightly over 20000 . Each subcenter is staffed by a trained female paramedic worker (LFPV) who provides clients with insertion services, treats side effects, removes Copper Ts, and provides clinical back up for other contraceptive methods. The LFPVs also conduct village visits to follow up special $\mathrm{MCH}$ and family planning problem cases and provide referral services to the project physician. Within the service area of each subcenter, 20 workers provide information, primary health care and oral pills and depo-medroxy progesterone acetate (DMPA) injections. These workers, known as Community Health Workers (CHWs), visit each of the households in the study villages fortnightly to encourage eligible women to accept family planning, to follow up the acceptors, and to provide limited but steadily expanding $\mathrm{MCH}$ services. Although first trimester abortions (menstrual regulation) are performed in government health centers, the Matlab Family Planning Health Services project does not offer such services. Therefore, none of the acceptors in the study are post abortion Copper $\mathrm{T}$ acceptors.

This study draws on the experience of 1418 women who accepted the Copper $T$ between May 1, 1978 and December 31, 1984. Complaints of side-effects were recorded during the bi-weekly home visits of the CHWs. Segments begin on the date of the first Copper $\mathrm{T}$ insertion, irrespective of whether the Copper $T$ is the initial method or the result of a switch from another method. Events of interest in the present analysis are pregnancies, expulsions, or removals for side effects and other reasons of termination of contraception occurring during the study period 1978-1984.

The age and parity composition of the 1418 women for the present study is shown in Table 1. The adopters of the Copper $T$ in Matlab are typically low to medium parity women under 30 years of age. Thus, effective continuous practice of contraception among these women will have pronounced fertility 
Table I. The composition of the Copper $\mathrm{T}$ acceptors by age and number of living children at the time of first Copper $T$ insertion.

\begin{tabular}{lrrrrr}
\hline $\begin{array}{l}\text { Age of } \\
\text { acceptor }\end{array}$ & \multicolumn{2}{l}{ No. of living childien } & Total \\
\cline { 2 - 5 } & None & $1-2$ & $3-5$ & $6+$ & \\
\hline$<20$ & 16 & 187 & 3 & 0 & 206 \\
$20-29$ & 5 & 415 & 317 & 1 & 738 \\
$30-39$ & 0 & 29 & 238 & 121 & 388 \\
$40+$ & 0 & 1 & 29 & 49 & 79 \\
& & & & & \\
Total & 21 & 632 & 587 & 171 & 1411 \\
No infor- & 0 & 5 & 1 & 1 & 7 \\
mation & & & & & \\
\hline
\end{tabular}

effects since a high proportion of acceptors are at peak childbearing ages.

It is also important to study the use effectiveness of the Copper $\mathrm{T}$ as its popularity is growing relative to other methods in the Bangladesh national family planning program. Figure 1 shows the trend in the prevalence of methods used in Matlab over the 1978-1984 period. Prevalence increased steadily so that by December of $1980,11 \%$ of contracepting women were using the device, and by December of 1981 15\% were Copper T users.

At the start of the program, insertions were

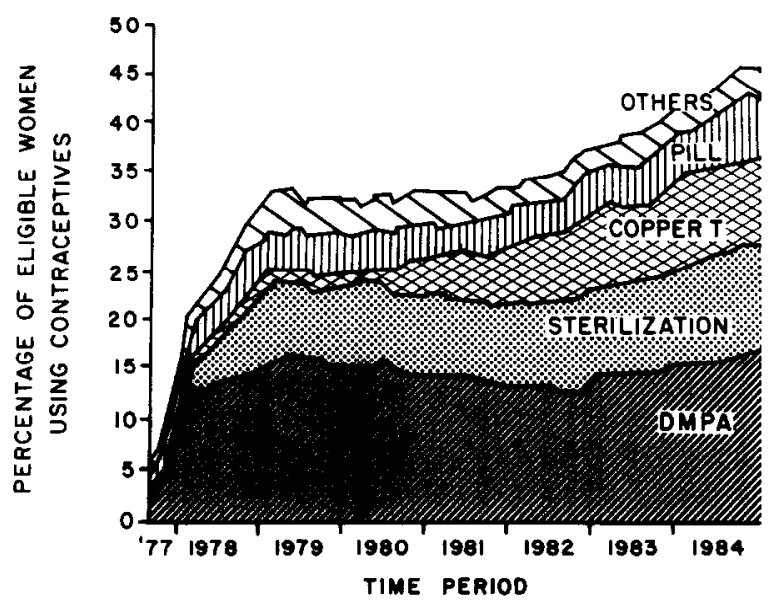

Fig. 1. Trends in prevalence of contraceptive use among married women of reproductive age, FPHSP treatment area, Oct 1977-Dec 1984. performed by the LFPV in the clinics. In 1981 , the steady rise in Copper T use prevalence that resulted from the clinical program was dampened somewhat by an apparent saturation of the population willing to travel to the subcenters for services. This apparent exhaustion of the population of potential Copper $T$ clients and the preliminary evidence of safety and effectiveness [2] led to a decision to extend insertion services to women in their homes. Accordingly, CHWs were instructed to identify women who sought home insertions and to liaison with LFPVs on scheduling the appropriate time for insertions to be performed. Each LFPV was given a simple field kit of equipment and special supplies for home insertions and instructed in special precautions required to maintain aseptic conditions and privacy. This action, in turn, led to a further increase in Copper T prevalence in 1982 and continued in subsequent years as shown in Fig. 1. By the end of the period of the current study, December 1984, 22\% of all contracepting women were using Copper $\mathrm{T}$. The data in Table I and Fig. 1 suggest that the Copper $T$ is an increasingly important modality: users are younger, lower parity women and Copper $T$ use prevalence is growing steadily with time. Moreover, increasing numbers of users are switching to the method. It is observed that more than half of the acceptors $(51.7 \%)$ have switched to Copper $\mathrm{T}$ from another method and the rest $(48.3 \%)$ have never used any method previously. In light of these trends, it is of interest to obtain a more detailed understanding of Copper T use-effectiveness in Matlab.

\section{Results}

\section{Continuation rates}

Continuation rates measure the probability that women who accept a method of contraception will still be protected at the end of a given period of time. Rates are usually stated in terms of number of continuing users per hundred acceptors at the end of a parti- 
cular ordinal month. The continuation rates presented in this paper have been computed by means of life table analysis as suggested by Potter [5]. Two types of continuation rates are considered in this paper: the first method continuation rate and the all method continuation rate. The former is the probability that an acceptor of a particular method will still be using the same method at the end of a given period of time. This is particularly useful for evaluating a family planning program that relies on only one method or for comparing experiences with individual methods in a multi-method program. The all method continuation rate measures the likelihood that a family planning acceptor will still be using any method of contraception at the end of a given period of time. Such rates are useful in evaluating multi-method programs, since they allow for the possibility that a woman who stops using one method may shift to another, possibly more suitable, method. The first and all method continuation rates by duration of time following acceptance are shown in Table II.

The findings for all method continuation rates are similar to findings for the first method rates, except that the all method rates are, by definition, higher than the corre-

Table II. First and all method cumulative continuation rates by ordinal month.

\begin{tabular}{|c|c|c|c|c|}
\hline \multirow{2}{*}{$\begin{array}{l}\text { Ordinal } \\
\text { month }\end{array}$} & \multicolumn{2}{|c|}{ First method ${ }^{\mathrm{a}}$} & \multicolumn{2}{|l|}{ All methods $b$} \\
\hline & $\begin{array}{l}\text { Cumulative } \\
\text { continua- } \\
\text { tion rate }\end{array}$ & $\begin{array}{l}\text { Standard } \\
\text { error }\end{array}$ & $\begin{array}{l}\text { Cumulative } \\
\text { continua- } \\
\text { tion rate }\end{array}$ & $\begin{array}{l}\text { Standard } \\
\text { error }\end{array}$ \\
\hline 3 & 0.967 & 0.0051 & 0.990 & 0.0028 \\
\hline 6 & 0.928 & 0.0074 & 0.978 & 0.0041 \\
\hline 12 & 0.823 & 0.0109 & 0.944 & 0.0067 \\
\hline 18 & 0.729 & 0.0127 & 0.899 & 0.0087 \\
\hline 24 & 0.616 & 0.0138 & 0.838 & 0.0107 \\
\hline 30 & 0.498 & 0.0144 & 0.773 & 0.0123 \\
\hline 36 & 0.414 & 0.0150 & 0.697 & 0.0144 \\
\hline 42 & 0.375 & 0.0155 & 0.647 & 0.0159 \\
\hline
\end{tabular}

${ }^{a} N=1209$.

${ }^{\mathrm{b}} N=1182$. sponding first method rates. One concludes from Table II that over $82 \%$ of the women who received a Copper $\mathrm{T}$ were still using a Copper $\mathrm{T}$ at the end of 1 year and that $62 \%$ were using a Copper $\mathrm{T}$ at the end of 2 years. Drop out rates are high during the third year, with only $41 \%$ of the adopters still using the device after 3 years. The corresponding all method continuation rates are $94.4 \%, 83.8 \%$ and $69.7 \%$ for 12,24 and 36 months, respectively, as shown in Table II.

\section{International comparison of Copper $T$ con- tinuation data}

Continuation rates from several Copper $\mathrm{T}$ programs in the developing or developed world have been compiled and presented in Table III to lend perspective to the first method continuation rates depicted for Matlab in Table II. In Matlab, first method continuation rates appear to be somewhat higher than India, Columbia, Iran and Korea. Reported 24 month Copper $\mathrm{T}$ continuation rates range between a low of $43 \%$ in lran [9], to a high of $69 \%$ in Sri Lanka [13] and Thailand [4]. Thus the Matlab rates are roughly comparable to Copper $\mathrm{T}$ continua-

Table III. International comparison of Copper $T$ first method continuation rates.

\begin{tabular}{|c|c|c|c|c|}
\hline \multirow[t]{2}{*}{ Country } & \multicolumn{4}{|c|}{ First method continuation rate } \\
\hline & $\begin{array}{l}6 \\
\text { months }\end{array}$ & $\begin{array}{l}12 \\
\text { months }\end{array}$ & $\begin{array}{l}24 \\
\text { months }\end{array}$ & $\begin{array}{l}36 \\
\text { months }\end{array}$ \\
\hline Sri Lanka ${ }^{b}$ & $\mathbf{N A}^{\mathbf{a}}$ & 81.0 & 69.0 & NA \\
\hline $\operatorname{India}^{c}$ & 80.1 & 69.2 & 52.0 & NA \\
\hline Columbia $^{d}$ & 86.1 & 78.2 & 52.0 & NA \\
\hline $\operatorname{Iran}^{d}$ & 85.5 & 71.5 & 42.8 & NA \\
\hline Korea $^{d}$ & 80.5 & 68.7 & 50.8 & NA \\
\hline Thailand $^{d}$ & 92.0 & 81.9 & 69.4 & NA \\
\hline \multicolumn{5}{|l|}{ Bangladesh } \\
\hline BFRPe & 78.5 & 71.9 & NA & \\
\hline Matlab & 92.8 & 82.3 & 61.6 & 41.4 \\
\hline $\begin{array}{l}\text { a NA, not av } \\
\text { b Wright [13 } \\
\text { c Sabita [7] } \\
\text { d Sivin [8]. } \\
{ }^{\text {e }} \text { Khan et al }\end{array}$ & $\begin{array}{l}\text { ailable. } \\
\text { ]. }\end{array}$ & & & \\
\hline
\end{tabular}


Table IV. First method net termination rates for decremental factors by ordinal month of exposure.

\begin{tabular}{|c|c|c|c|c|c|c|}
\hline \multirow{3}{*}{$\begin{array}{l}\text { Ordinal } \\
\text { month }\end{array}$} & \multicolumn{6}{|c|}{ Reasons for Copper $\mathrm{T}$ terminations } \\
\hline & \multicolumn{2}{|l|}{ Pregnancy } & \multicolumn{2}{|l|}{ Expulsion } & \multicolumn{2}{|l|}{ Removal } \\
\hline & $\begin{array}{l}\text { Cumulative } \\
\text { termination } \\
\text { rate }\end{array}$ & S.E. & $\begin{array}{l}\text { Cumulative } \\
\text { termination } \\
\text { rate }\end{array}$ & S.E. & $\begin{array}{l}\text { Cumulative } \\
\text { termination } \\
\text { rate }\end{array}$ & S.E. \\
\hline 3 & & & 0.088 & 0.0027 & 0.024 & 0.0045 \\
\hline 6 & 0.001 & 0.0009 & 0.022 & 0.0044 & 0.050 & 0.0065 \\
\hline 12 & 0.009 & 0.0030 & 0.054 & 0.0071 & 0.114 & 0.0102 \\
\hline 18 & 0.014 & 0.0036 & 0.083 & 0.0090 & 0.174 & 0.0129 \\
\hline 24 & 0.021 & 0.0048 & 0.094 & 0.0097 & 0.268 & 0.0168 \\
\hline 30 & 0.023 & 0.0051 & 0.101 & 0.0103 & 0.377 & 0.0215 \\
\hline 36 & 0.024 & 0.0054 & 0.110 & 0.0115 & 0.451 & 0.0256 \\
\hline 42 & 0.024 & 0.0054 & 0.111 & 0.0115 & 0.491 & 0.0286 \\
\hline
\end{tabular}

tion rates reported elsewhere in the region, although considerable variation from study to study is suggested by the data in Table III.

Reasons for termination of the first method

Net conditional termination rates have been calculated for three general causes of termination: pregnancy, expulsion and removal. Table IV presents net termination rates for these three causes and demonstrates that removal of the IUD is clearly a more important cause of termination than involuntary reasons such as expulsion or method failure. Figure 2 diagrams these rates and shows a leveling of the expulsion curve by 18 months so that the $36-$ month rate is double that of the 12-month rate. This suggests that women who cannot tolerate the device expel it early and women who retain the device for a year are at lower risk of expulsion from the second year onward than ncw adopters. Net removal rates, on the other hand, increase linearly with time, indicating a constant removal rate not specific to any specific segment in the use period.

In the following section, we present net termination rates for each decremental factor individually, although their joint effects on the continuation rate can be ascertained by simple addition. Since we are focusing speci- fically on the Copper T, our discussion will be addressed primarily to first method net termination rates. In the presentation that follows, we first discuss net cumulative pregnancy, expulsion, and removal rates.

\section{First method net pregnancy rate}

Results from other research studies of Copper $T$ pregnancy rates report net conditional 12 month failure rates ranging from 0 to $5 \%$ after 1 year and $2.2 \%$ after 2 years of

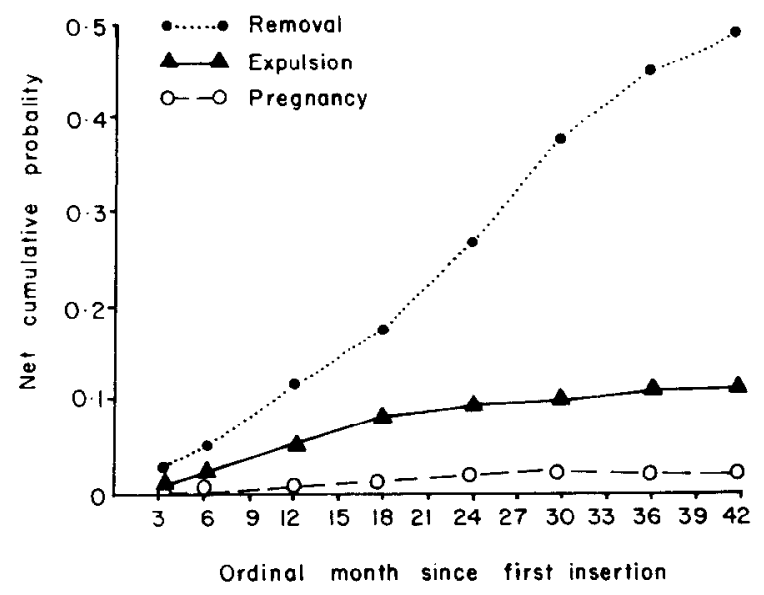

Fig. 2. Net cumulative probability of terminating the Copper $\mathrm{T}$ due to removal, expulsion and pregnancy. 
use as calculated by the Potter multiple decrement life table technique. One large Copper T study involving 26760 women-months of observation reported a net cumulative 12 month pregnancy rate of $3.5 \%$ [4]. A comparative study of the Copper $\mathrm{T}$ and Lippes Loop conducted in five developing countries by Sivin [8], reported net risks of Copper T failure consistent with or below corresponding risks among loop users. Indeed, Sivin demonstrated that failure rates for the Copper $\mathrm{T}$ are among the lowest encountered for any IUD. The Matlab results corroborate the high rates of Copper $\mathrm{T}$ effectiveness reported by Sivin. As Figure 2 shows net cumulative failure rates plateau at $2.2 \%$ by month 24. While exhaustion of the copper in the device can result in elevated risk of failure, Figure 2 shows that failure rates do not increase with time and thus afford no evidence to suggest rising risks of device failure owing to exhaustion of copper. The net cumulative failure rate remains the same even after 42 months. But it should be kept in mind that in Matlab study area LEFVs are instructed to remove Copper $\mathrm{T}$ within 3 years. Thus in few cases acceptors have used Copper $\mathrm{T}$ more than 3 years.

\section{Expulsion}

Expulsion of the device, especially in younger, low partiy women has heretofore been a major problem with non-copper IUDs. The rate of expulsion varies according to the type of device used. In separate Population Council studies by Lewit and Tatum it was shown that after 1 year, Copper $\mathrm{T}$ devices were better retained than the Lippes Loop $[4,10]$. The Matlab data accord well with this early evidence of high Copper $T$ retention rates. First method net expulsion rates for Matlab are $9.4 \%$ at 24 months, $10.1 \%$ at 30 months, and $11.0 \%$ at 36 months (Table IV). As we noted above, the shape of the expulsion curve in Fig. 2 is indicative of declining risks with time. The data suggest that expulsion risks in Matlab are similar to those reported in an Indian study [7], where it was found that $9.6 \%$ expel the device by month 24 and $10.4 \%$ by month 30 .

\section{Reasons for removal}

The data in Table IV demonstrate that at 12, 24 and 36 months, the first method removal rates of the Copper $T$ are 11.4, 26.8 and 45.1 , respectively. Since removal is such an important component of method discontinuation this factor is subdivided into removal owing to complaints of side effects, to the desire for more children, to no need and other reasons for stopping or switching to another method. The category "no need" includes women who are divorced, widowed, separated or otherwise not at the risk of pregnancy. Table $\mathrm{V}$ shows that about one third of the removal rate is attributable to complaints associated with side effects. By month 36 nearly $14 \%$ of all users terminate owing to complaints attributed to method side effects. The data in Table $\mathrm{V}$ shows, moreover, that termination risks for other reasons for removal are relatively minor. Thus, side effects are a primary factor behind stopping use of the Copper $T$ and management of such problems is an important determinant of program performance. This issue is considered in greater detail below.

\section{Side effects and their management}

In the Matlab service system a field record is compiled for each fortnightly visit of a $\mathrm{CHW}$ to an eligible woman. Women are asked about their use of family planning and any physical complaints that they have at that time. Those complaints which are associated with the method are noted in the field record book along with the action taken. This system is obviously flawed in that any complaint perceived or real that a woman associates with contraceptives is recorded as a "side effect" even if the association of the complaint with the device is spurious. Nevertheless the recording of complaints is instructive because it indicates the extent to which minor health problems are occurring and are perceived to be or actually associated with contraception by the client population. 
Table V. First method net removal rates and rates for corresponding subdecremental factors by ordinal month of exposure.

\begin{tabular}{|c|c|c|c|c|c|c|c|c|c|c|}
\hline \multirow{3}{*}{$\begin{array}{l}\text { Ordinal } \\
\text { month }\end{array}$} & \multicolumn{10}{|c|}{ Reasons for Copper T removal } \\
\hline & \multicolumn{2}{|c|}{ Side effects } & \multicolumn{2}{|c|}{$\begin{array}{l}\text { Want more } \\
\text { children }\end{array}$} & \multicolumn{2}{|c|}{ No need } & \multicolumn{2}{|l|}{ Other } & \multicolumn{2}{|l|}{ Total } \\
\hline & $\mathrm{CTR}^{\mathrm{a}}$ & S.E. ${ }^{b}$ & CTR & S.E. & CTR & S.E. & CTR & S.E. & CTR & S.E. \\
\hline 3 & 0.020 & 0.0041 & 0.000 & - & 0.002 & 0.0012 & 0.003 & 0.0015 & 0.024 & 0.0045 \\
\hline 6 & 0.032 & 0.0053 & 0.002 & 0.0012 & 0.003 & 0.0017 & 0.012 & 0.0030 & 0.050 & 0.0065 \\
\hline 12 & 0.053 & 0.0069 & 0.018 & 0.0041 & 0.008 & 0.0026 & 0.035 & 0.0056 & 0.114 & 0.0102 \\
\hline 18 & 0.071 & 0.0082 & 0.030 & 0.0055 & 0.013 & 0.0035 & 0.060 & 0.0077 & 0.174 & 0.0129 \\
\hline 24 & 0.095 & 0.0099 & 0.060 & 0.0082 & 0.014 & 0.0038 & 0.098 & 0.0103 & 0.268 & 0.0168 \\
\hline 30 & 0.116 & 0.0115 & 0.092 & 0.0110 & 0.020 & 0.0049 & 0.148 & 0.0137 & 0.377 & 0.0215 \\
\hline 36 & 0.141 & 0.0141 & 0.116 & 0.0137 & 0.024 & 0.0058 & 0.169 & 0.0156 & 0.451 & 0.0256 \\
\hline 42 & 0.151 & 0.0154 & 0.133 & 0.0160 & 0.025 & 0.0063 & 0.181 & 0.0170 & 0.491 & 0.0286 \\
\hline
\end{tabular}

${ }^{a}$ CTR, cumulative termination rate.

b S.E., standard error.

Although 1418 women accepted Copper T by the end of December 1984, CHWs recorded information from first 2 years acceptors about side effects. Of the 629 women who are asked to describe their side effects, $449(42.4 \%)$ expressed a complaint to the CHW on the last visit in which the Copper $\mathrm{T}$ was in use. Such a high rate of complaints quite obviously cannot be attributed solely to contraception. Equally obvious, however, is the conclusion that one draws from such findings: when minor ailments are so common, careful attention to health problems is a critical component of program success. Fully $46.8 \%$ complained of bleeding, nearly a third of some body pain, one fourth of other weakness and another one-fourth of some other problem. Of the 449 with a complaint, nearly half had two or more complaints. "Treatment" by the CHW typically involves giving aspirin for dizziness, pain, or fever, or referral to the subcenter clinics where antibiotics can be provided if needed. Of the 267 women with complaints, $244(91 \%)$ were provided with something - either aspirin, iron tablets, or referral services and care at the subcenter clinics. One-half of the care for these 244 women was provided in the village by the CHW and nearly half by the LFPV in the subcenters, with the remainder by the physician in the Matlab central clinic. The data show evidence of a strong system of support: many women complained of an ailment and associated it with the device, but most were provided with care either in their homes, subcenters or in the central clinic. It is reasonable to hypothesize that this support system is a key factor behind continuity of use.

Evidence in support of this hypothesis appears from the difference between first and last method life table termination rates. While there is a net cumulative conditional probability of $14 \%$ that a user will terminate the Copper $\mathrm{T}$ within 3 years because of complaints, the corresponding rate for all methods combined is less than $6 \%$. The impact of side effects on the continuation rate is thus substantially reduced for the last method used, indicating that a significant prolongation of contraceptive practice accrues from method switching. Matlab workers are instructed to advise women to switch methods when problems and complaints arise.

\section{Summary and Implications}

The Copper $\mathrm{T}$ is a highly effective contraceptive modality in Matlab, with use effectiveness that compares favorably with IUD rates 
observed elsewhere and efficacy that is superior to rates typically observed for methods such as pills and condoms - methods which require sustained motivation and regular resupply. The Matlab findings indicate, however, that Copper $\mathrm{T}$ adoption does not obviate the need for regular attention to users. First method continuation rates are significantly lower than all method rates. Many users who stop using Copper Ts do so because of complaints. They nevertheless continue use because a trained and sympathetic worker attends to their problems and offers an alternative method. The implication of this is that a single method Copper $\mathrm{T}$ program without rigorous follow up would be much less successful than the Matlab system where many methods are freely available and intensive follow up and referral supports use of all methods of contraception. While the Copper $\mathrm{T}$ is thus a highly effective method with growing popularity in Matlab, its efficacy and popularity cannot be attributed to the method alone - care and attention to users and the availability of multiple methods are critical determinants of the success of the Copper $\mathrm{T}$ insertion program in Matlab.

\section{References}

1 Bhatia S, Mosley WH, Faruque AGS, Chakraborty J: The Matlab Family Planning Health Services Project. Stud Fam Plann 11: 6, 1980.

2 Chakraborty J, Zimicki S, Chowdhury AI, Jahan N, Phillips JF: The Matlab Experience with the Copper $T$ Intrauterine Device. Paper presented at the Biannual Conference on Operations Research, National Institute for Population Research and Training, held on August at Dhaka, Bangladesh, 1982.

3 Khan AR, Khanam F, Jahan FA: A Comparative Study of Copper T-220C and Lippes loop C, Presented at the Annual Contributors Conference of BFRP, held on November at Dhaka, Bangladesh. 1979.
4 Lewit S: Two years experience with the Copper T: A research report. Stud Fam Plann 4: 7, 1973.

5 Potter RG: The multiple decrement life table as an approach to the measurement of use effectiveness and demographic effectiveness of contraception. In A Handbook for Service Statistics in Family Planning Programs (ed JA Ross et al.) pp 124-138. The Population Council, New York, 1969.

6 Rahman M, Mosley WH, Khan AR, Chowdhury AI, Chakraborty J: Contraceptive distribution of Bangladesh: some lessons learned. Stud Fam Plann 11: 6, 1980.

7 Sabita T, Sexna NC, Malhotrev U, Chowdhury SR: Experience with Copper $T$ in India. Proceedings of Third International Conference on Intrauterine Contraception, held on December at Cairo, Arab Republic of Egypt. 1974.

8 Sivin I: The effectiveness of the Copper $\mathrm{T}$ intrauterine device: a collaborative study in five countries. Stud Fam Plann 4: 7, 1973.

9 Sivin I: Two Years of Experience with Copper T: A Study in Four Developing Countries. The Population Council, New York, 1975.

10 Tatum HJ: Intrauterine contraception. Am J Obstet Gynecol 112: 1, 1972.

11 Tatum HJ, Zipper JA: Proceedings of the VI Northeast Obstetrical and Gynecological Congress of Brazil. held on October at Salvador, Bahia, Brazil. 1968.

12 Tietze $C$, Lweit $S$ : Comparison of the Copper $T$ and Loop D: a research report. Stud Fam Plann 3: 11, 1972.

13 Wright NH: Ceylon Survey Comparing Loop and Oral Contraceptive Acceptor. Some Preliminary Results. Unpublished, 1970.

14 Zipper JA, Medel M, Prager R: Suppression of fertility by intrauterine copper and zinc in rabbits. Am J Obstet Gynecol 105: 15, 1971.

15 Zipper JA, Tatum HJ, Medel M, Pastene L, Rivera M: Contraception through the use of intrauterine metals. I. Copper as an adjunct to the $\mathbf{T}$ device. Am $\mathrm{J}$ Obstet Gynecol 109: 1, 1971.

Address for reprints:

Dr. Ubdaidur Rob

International Centre for Diarrhoeal Disease Research

G.P.O. Box 128 Dhaka-2

Bangladesh 